\title{
Older Drivers' Performance at Intersections: An Experimental Study in Italy
}

\author{
Natalia Distefano, Salvatore Leonardi ${ }^{*}$ \\ Department of Civil Engineering and Architecture, University of Catania, Italy \\ Received July 30, 2021; Revised September 2, 2021; Accepted October 17, 2021
}

\section{Cite This Paper in the following Citation Styles}

(a): [1] Natalia Distefano, Salvatore Leonardi , "Older Drivers' Performance at Intersections: An Experimental Study in Italy," Civil Engineering and Architecture, Vol. 10, No. 1, pp. 253-266, 2022. DOI: 10.13189/cea.2022.100122.

(b): Natalia Distefano, Salvatore Leonardi (2022). Older Drivers' Performance at Intersections: An Experimental Study in Italy. Civil Engineering and Architecture, 10(1), 253-266. DOI: 10.13189/cea.2022.100122.

Copyright $\mathrm{C} 2022$ by authors, all rights reserved. Authors agree that this article remains permanently open access under the terms of the Creative Commons Attribution License 4.0 International License

\begin{abstract}
Longer life expectancy is leading to an increase in the average age of the European population. In $2018,20 \%$ of the population was over 65 years old. In 2070, $30.3 \%$ of the population will be over 65 . Older people prefer to walk in their neighborhoods but they rely on cars as their primary mode of transportation, which allows them to maintain their autonomy over long distances. However, age-related physical impairments can have a significant impact on driving skills, including the ability to properly visualize driving scenarios. Numerous studies have shown that older drivers have significant safety problems at standard intersections rather than roundabouts $(40 \%$ of fatal crashes occur at standard intersections among drivers 70 years and older). In this work, it was decided to study a specific parameter representative of the behavior of all road users when preparing for the typical maneuvers at stop-controlled intersections (crossing, right-turn and left-turn). This parameter is the gap accepted by elderly road users at different stop-controlled intersections and under homogeneous traffic conditions. For this purpose, a research campaign was organized with 37 elderly drivers performing all possible maneuvers at 9 intersections in Italy (Eastern Sicily). The experimentally determined values of the critical gap for left-turn and crossing maneuvers were found to be compatible with those of the main internationally used reference manuals for road design. The value of the critical $50^{\text {th }}$ percentile gap $\left(\mathrm{G}_{50}\right)$ for the right-turn maneuver was similar to that for the left-turn maneuver. This is an indication of a very similar level of difficulty for older drivers in performing both turning maneuvers. The results of this study have highlighted the need to take into account the different
\end{abstract}

operational difficulties associated with the possible maneuvers at intersections. The theoretical approaches of the Italian legislation are carried out, based on a criterion that does not distinguish according to the way in which the three maneuvers, which proves to be totally inadequate. This suggests a complete revision of the criteria for checking sight distances at stop-controlled intersections.

Keywords Older Drivers, Road Safety, Stop-controlled Intersections, Logistic Regression, Critical Gap, HCM, Green Book

\section{Introduction}

The proportion of older people (typically defined as $\geq 65$ years $[1,2])$ in society is steadily increasing worldwide.

According to the European Statistical Institute, Eurostat, the average life expectancy at birth for the inhabitants of the 27 European countries, which today is 78.2 years for men and 83.7 years for women, is expected to reach 86.1 years for men and 90.3 years for women in 2070. Indeed, data for 2018 show that the years European citizens live in good health average 64.2 for women and 63.7 for men. When it comes to European averages, there is a lot of variation. A Swedish man lives about 73 years of his life in good health, while a Latvian lives only 51 . For Italians, in men and women almost in equal proportions, the prospect of living in good health is now about 70 years. Not only are Italians getting older, they are also having fewer children. The birth rate in 2018 was 1.55 children per woman. But, to 
keep the population constant, without taking into account the contribution of immigrants' children, 2.1 children per woman are required. Hardly any region in Europe has a rate at this level. Women are giving birth less and are also no longer very young when they give birth for the first time: in 2001 the average was 29 , in 2018 it was 31 . The sum of higher life expectancy and lower birth rates is leading to an increase in the average age of the European population. In 2018, 20\% of the population was over 65 (and even then, Italy was the oldest country in Europe, with $22.6 \%$ of the population over 65 ). In $2070,30.3 \%$ of the population will be over 65 and only $51 \%$ will be of working age (20-64 years), compared to $59 \%$ in 2019 [3].

The older population accounts for about a quarter of all licensed drivers in the world [4]. In 2018, 6,907 drivers older than 65 were killed on Unites States (U.S.) roads, accounting for $19 \%$ of all U.S. traffic fatalities [2].

The average age of road traffic victims in the EU is increasing: older people aged 65 and over accounted for $28 \%$ of all road traffic fatalities in 2018 , compared to $22 \%$ in 2010. While fatal crashes involving users aged 18-24 decreased by $43 \%$ during $2010-2018$, the number of users aged 65 and older who were victims of road accidents increased by about $2 \%$ [5].

In modern life, older people prefer to walk in their neighborhoods [6-8], but like all age groups, they rely on cars as their primary mode of transportation, which allows them to maintain their autonomy over long distances [9]. However, as people age, decline in motor skills, vision, somatosensory functions and cognition increases, which can have a significant impact on driving skills, including the ability to correctly visualize the driving scenario and understand the dynamics occurring there $[10,11]$. For example, older drivers with visual impairments (e.g., glaucoma, macular degeneration, cataracts, etc.) have difficulty recognizing details of intersection features such as shoulders, curbs, and traffic islands; seeing other road users such as bicyclists and pedestrians; scanning the traffic environment for potential hazards; and seeing traffic signals and reading signs [12-14]. In addition, older drivers with physical limitations (e.g., arthritis) may find intersections crossing more difficult because they are less able to perform vehicle control actions, avoid collisions with other vehicles, and react appropriately and quickly to unusual events $[15,16]$. Older drivers with perceptual and cognitive impairments may also have difficulty navigating complex traffic and performing complex maneuvers such as left turns or lane changes [17-19]. At a complex intersection that requires the integration of much visual information, quickly interpreting the most important stimuli is a difficult task for older users, which may lead to inaccurate perception or even complete overlooking of important perceptual cues [20,21].

Researchers suggest that frailty, illness, and medication use contribute significantly to the crash differences between older and younger drivers and the increased risk of injury and death among older drivers [22, 23].
Data from Bédard et al. [24] showed that elderly drivers were more vulnerable to the traumatic effects of collisions. Older drivers (65-79) were 2.3 times more likely to suffer a fatal injury than drivers aged 40-49; drivers older than 80 were as much as five times more likely to suffer a fatal injury than younger drivers.

Numerous studies in the literature have shown that older drivers exhibit significant safety problems at road intersections. As a result, this category of road users is characterized by the highest rates of accidents at intersections. Safety issues for older drivers primarily affect standard at-grade intersections, as roundabouts, although not particularly popular with this user group [25], do not have features that would be particularly dangerous for older drivers [26].

In fact, $40 \%$ of the fatal crashes occur at standard intersections for drivers aged 70 and older, compared to only $23 \%$ for younger drivers [27 It has also been reported that between $48 \%$ and $55 \%$ of the fatal accidents involving drivers aged 80 years or older occurred at junctions, more than double the rate for drivers aged 50 years or less $(23 \%)$ [28]. Stamatiadis et al. [19] indicate that drivers older than 65 years and younger than 25 years were more likely than other age groups to be involved in crashes at both signalized and unsignalized intersections. Previous research has also confirmed that older drivers are more likely to be involved in accidents when turning left [29-32].

The results of a driving simulator study [33] suggest that older users (65.6 \pm 5 years) have some limitations, especially when turning left against oncoming traffic and overtaking a vehicle in front. It has also been demonstrated that older drivers (65-80 years) had a significantly lower proportion of visual scanning on the left and right sides during road junctions crossing compared to younger (18-25 years) and middle-aged (35-55 years) users [34].

At stop-controlled intersections, drivers on the minor road must use appropriate gaps in traffic to cross or merge into the major road. Since the driver's gap acceptance maneuver is a complex and risky driving behavior, it is a very important issue for traffic safety and operation. Retting et al. [35] reported that nearly 700,000 motor vehicle crashes occur at stop signs in the U.S. each year, and about one-third of these crashes involve injuries. During the period from 2000 to 2002, more than 34,000 traffic crashes occurred on rural two-lane roads in Minnesota. More than $32 \%(11,069)$ of these crashes were intersection-related, with $22 \%$ of rural fatal crashes occurring at stop-controlled intersections [36]. Previous research has identified gap acceptance problems as a significant contributor to crashes at traffic signal-controlled intersections, suggesting that incorrect gap acceptance may cause approximately $30 \%$ of the left-turn crashes [37]. As an essential driving behavior at stop-controlled intersections, the gap assumption decision has been used as an important measure to analyze traffic conflicts and crash rates at road intersections $[38,39]$.

The current American Association of State Highway and 
Transportation Officials manual (AASHTO manual 2018) [40], known as the Green Book, uses gap assumption methodology to determine intersection sight distances based on previous research [41]. In the current Highway Capacity Manual (HCM 2016) [42], the critical gap accepted by motorists is a key parameter for calculating lower traffic capacity. However, both major highway design manuals ignored the effects of important factors on gap acceptance, which has been generally noted by researchers in traffic safety aspects [43].

A review of the gap acceptance literature showed that driver behavior is influenced by several factors. Most variables are related to traffic conditions such as gap size $[44,45]$, waiting time in the queue [46] or at the stop line $[45,47,48]$. In addition to the above factors, Bottom and Ashworth [44] suggest examining the extent to which age, personality, annual mileage, and vehicle type actually influence drivers' different behaviors.

Typically, the acceptance of small gap size leads to an increased likelihood of traffic accidents [49].

An analysis of police-reported crashes in the U.S. found the most common type of critical error among drivers aged 70 years or older was misjudging the gap size of the approaching vehicle [50]. In terms of personal characteristics, experimental research showed that novice users tend to take more gaps and are more likely to accept shorter gaps compared to more experienced drivers [51].

It has been reported the process of driving performance getting worse with age accelerates somewhere in the fifth decade of life [2]. Older drivers have problems adequately recognizing, perceiving, and correctly judging the safety of a gap [36]. Therefore, older drivers may have greater difficulty at unsignalized intersections due to their limited visual abilities, such as depth and motion perception. In this regard, Lyles and Staplin [52] studied police-reported crashes in Michigan and Pennsylvania and found that when ranked by older driver involvement, turning left into oncoming traffic and crossing or turning into a stream of traffic were considered the most dangerous maneuvers. Understanding the factors that influence the outcome of gap closure decisions can be useful for supporting transportation planning and increasing the safety and efficiency of the roadway network.

What has been said so far has motivated the authors of this study to conduct research aimed at filling the gap in scientific research regarding the understanding of safety levels associated with the behavior of older drivers (over 65 years of age) approaching stop-controlled intersections. In accordance with the studies cited above, it was decided to study a specific parameter representative of the behavior of all road users when preparing to perform the different types of maneuvers (crossing, right-turn and left-turn) that can be performed at the stop-controlled intersections with 3 or 4 legs. It was therefore decided to study the gap accepted by elderly users at different stop-controlled intersections and in homogeneous traffic conditions. For this purpose, a research campaign was organized involving 37 elderly drivers performing all possible maneuvers at 9 intersections in Italy (specifically on some road networks in Eastern Sicily).

Through the statistical treatment of the accepted gap values, it was possible to determine the $\mathrm{G}_{50}$ values (critical interval, defined as the time interval accepted by $50 \%$ of the users) characteristic of the possible maneuvers performed by drivers over 65 years old.

The final discussion will be broad and articulate and, above all, will allow a critical analysis of the current criteria for checking sight distances in intersections proposed by the main road design manuals.

In addition, the implications that the results of this study could have on the Italian legislation on the design of intersections (M.D. 10/04/2006, [53]) will be critically presented. In particular, the need to review the check criteria for sight distances at stop-controlled intersections will be adequately justified to ensure equal levels of safety for users of all ages.

\section{Materials and Methods}

\subsection{Participants}

Thirty-seven participants aged 65 to 85 years were recruited in this study. The test-drivers were divided into two age groups, one consisting of drivers aged 65 to 75 years and the other consisting of drivers over 75 years. Initially, 50 test-drivers were recruited, but 13 were excluded because they had declared to suffer from serious diseases after a preliminary interview. Specifically, the 13 excluded participants had one or both of the following pathologies:

- Severe hearing problems. The problem complained of was hearing loss, which initially causes a reduction in sensitivity to sounds at higher frequencies $(18-20 \mathrm{kHz})$ and gradually affects sounds at lower frequencies. High frequency hearing loss makes word discrimination particularly difficult, especially in the presence of background noise. Against this background, it should be recalled that art. 473 of the Italian Road Code states that "to obtain a driving license for private use for vehicles of classes A and B, it is necessary to perceive the conversational voice with combined phonemes in each ear at a distance of not less than two meters" [54].

- Serious problems performing certain movements (e.g., turning the head or turning the torso). Specifically, the declared pathologies were arthrosis, rheumatism or other pathologies related to the aging of the human body.

The descriptive statistics of the sample are presented in Table 1. 
Table 1. Descriptive statistics of the sample

\begin{tabular}{|c|c|c|c|c|c|c|c|}
\hline Variable & Intervals & Freq. & $\%$ & Mean & Std. Dev. & Min & $\operatorname{Max}$ \\
\hline \multirow[t]{3}{*}{ Gender } & Female & 14 & 38 & - & - & - & - \\
\hline & Male & 23 & 62 & - & - & - & - \\
\hline & Total & 37 & 100 & - & - & - & - \\
\hline \multirow{3}{*}{$\begin{array}{l}\text { Age } \\
(65-75)\end{array}$} & Female & 8 & 22 & 70.62 & 3.18 & 65 & 75 \\
\hline & Male & 12 & 32 & 69.42 & 2.81 & 65 & 74 \\
\hline & Total & 20 & 54 & 69.90 & 3.21 & 65 & 75 \\
\hline \multirow{3}{*}{$\begin{array}{l}\text { Age } \\
(>75)\end{array}$} & Female & 6 & 16 & 78.33 & 2.73 & 76 & 83 \\
\hline & Male & 11 & 30 & 80.36 & 2.69 & 76 & 85 \\
\hline & Total & 17 & 36 & 79.65 & 2.80 & 76 & 85 \\
\hline Age (All) & Total & 37 & 100 & 74.38 & 5.76 & 65 & 85 \\
\hline Driving experience & Total & 37 & 100 & 52.97 & 5.72 & 44 & 64 \\
\hline \multirow{4}{*}{ Frequency of driving } & Daily & 25 & 67 & - & - & - & - \\
\hline & 2-3 times/week & 8 & 22 & - & - & - & - \\
\hline & Once a week & 4 & 11 & - & - & - & - \\
\hline & Less/often & 0 & 0 & - & - & - & - \\
\hline \multirow{2}{*}{$\begin{array}{l}\text { Minor accident } \\
\text { involvement }\end{array}$} & No & 31 & 84 & - & - & - & - \\
\hline & Yes & 6 & 16 & - & - & - & - \\
\hline \multirow{2}{*}{$\begin{array}{c}\text { Major accident } \\
\text { involvement }\end{array}$} & No & 37 & 100 & - & - & - & - \\
\hline & Yes & 0 & 0 & - & - & - & - \\
\hline \multirow{2}{*}{ Ticket for speeding } & No & 34 & 92 & - & - & - & - \\
\hline & Yes & 3 & 8 & - & - & - & - \\
\hline
\end{tabular}

The mean age of the participants was approximately 74 years and the corresponding standard deviation was 5.76 years. For both age groups, there were no significant differences between the mean ages of males and females. The oldest test-driver was an 85-year-old male.

All 37 test drivers had the following requirements, which were considered correct for conducting the experimental investigation:

- driving experience over forty years (on average, the driving experience of the test drivers was about 53 years);

- $\quad$ regular use of the car (at least once a week);

- no serious accidents during their many years of driving. An accident was considered serious if at least one person had to be treated medically and/or property damage of more than $€ 500$ was caused;
- almost impeccable driving behavior (only 3 drivers stated they had received a ticket for speeding).

\subsection{Experiment Design}

An experimental investigation was organized to evaluate the behavior of elderly users at intersections regulated by the stop sign. In particular, the investigation aimed to estimate the acceptance time intervals (critical gap) on the main traffic flow by elderly users about to perform one of the possible maneuvers (crossing, right-turn and left-turn) starting from the stop line.

Nine intersections in Eastern Sicily were selected (3 in the territory of Modica in the province of Syracuse and 6 in the municipality of Catania). Four intersections were type 3-leg and five were type 4-leg (Fig. 1). 


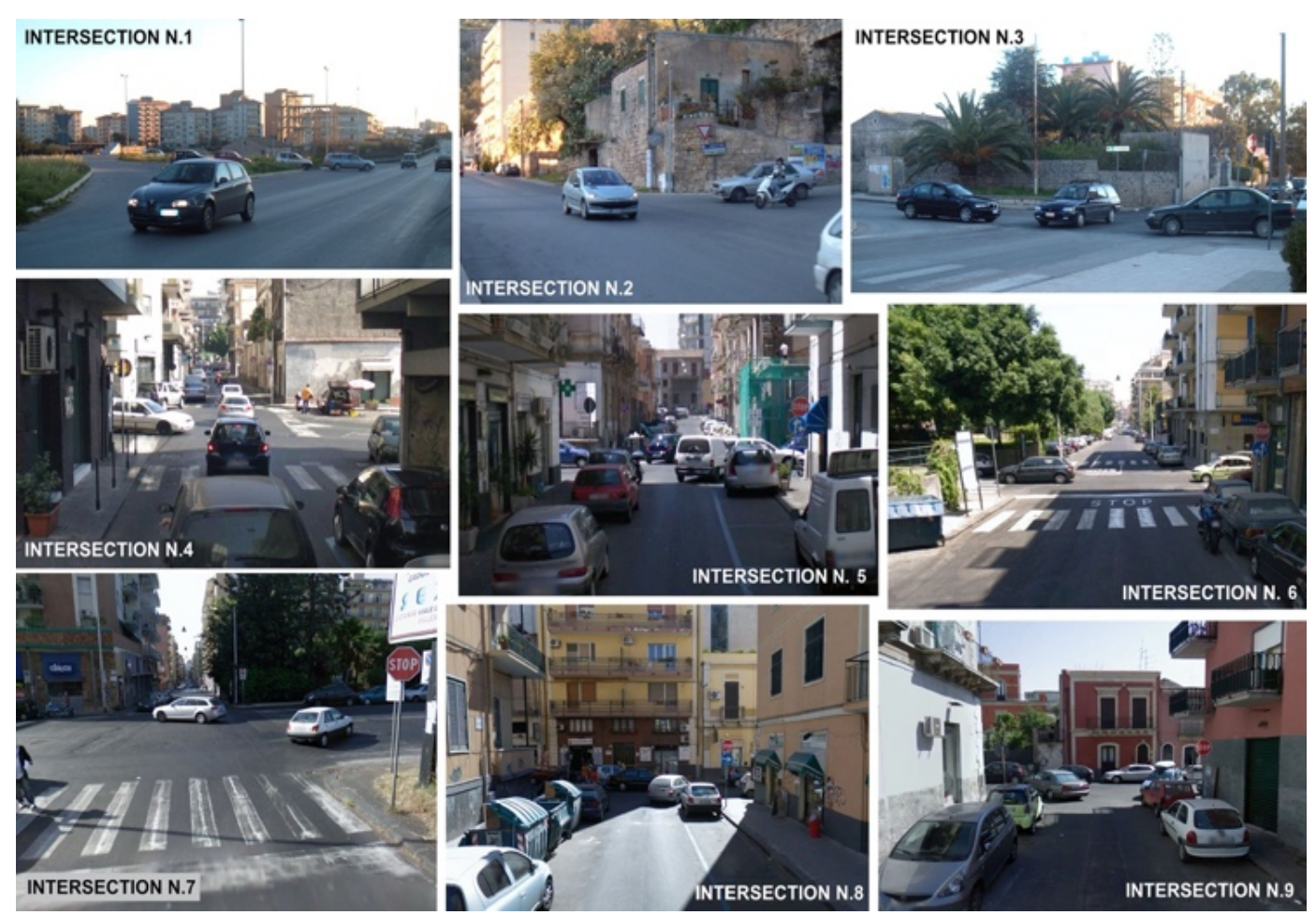

Figure 1. The nine intersections which are the subject of experimental investigation

Each of the test drivers performed each maneuver 10 times at the selected intersections (crossing, left and right-turns). In order not to induce excessive fatigue in the different test-drivers, each of them was asked to repeat the maneuvers with a maximum cadence of 2 times per day.

Different maneuvers were filmed with video cameras capable of recording high resolution movies, where it was not possible to position oneself at a suitable height to film the entire intersection area from above, simultaneous footage was instead taken from two angles using two video cameras suitably hidden from the view of vehicle drivers.

Each of the vehicles selected for the investigations, driven by older people, was made identifiable by placing adhesive films on the doors and roof, which were a different color depending on the age of the drivers (yellow films for drivers between 65 and 75 years and red for those over 75 years); this was done to facilitate the identification of the test drivers during the subsequent video analysis phase.

Investigations were always conducted on weekdays (from Monday to Friday), at times of day when traffic conditions on the main route were far from congested, but also when driving was not at high speeds. In this way, very similar traffic conditions were obtained for all 9 intersections studied.

\subsection{Video Processing Phase}

After downloading all the videos acquired during the investigation campaign to a personal computer, the time intervals accepted by the elderly drivers of the vehicles waiting on the stop line were timed with the support of the Quick Time Player software.

Figure 2 illustrates the criterion for measuring the acceptance time in the case of a right-turn (the procedure is the same for crossing and left turning maneuvers). The reference time $t_{1}$ corresponds to the instant in which vehicle $B$ on the main road is exactly in front of vehicle $A$ stopped at the stop line. The time $t_{2}$, on the other hand, is the one in which vehicle A entered the passage left free by two consecutive vehicles (B and C) present on the main road. The acceptance time (critical gap) is therefore identified by the interval $G=t_{2}-t_{1}$.

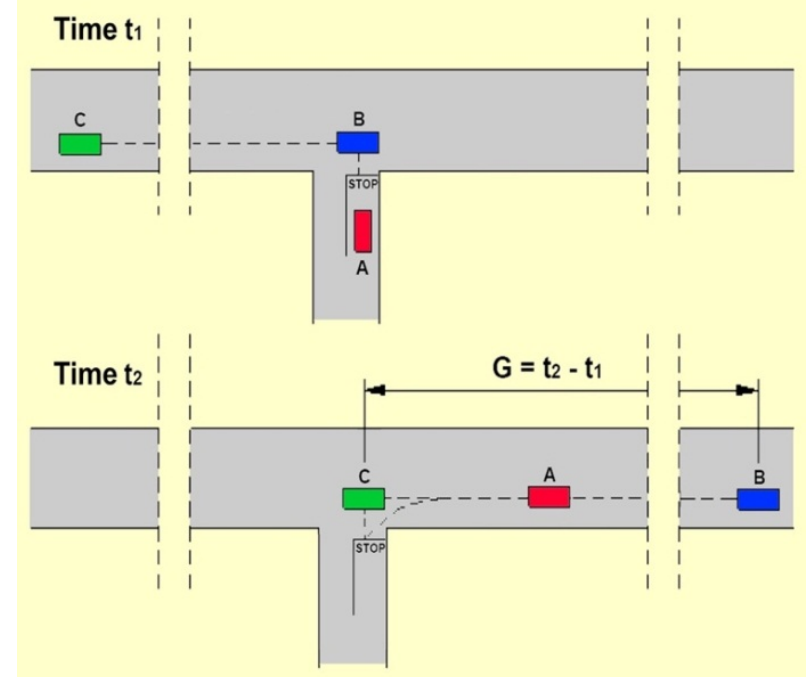

Figure 2. Criterion for measuring the acceptance time (right-turn) 
Thanks to the analysis of all the recorded videos, it was also possible to evaluate the average speed of the flow of vehicles on the main road in all the situations where the vehicle at the stop line was one of the vehicles driven by the test-drivers recruited for the experiment. These speeds represented the discriminating parameters for the selection of the acceptance intervals. In fact, the criterion of considering valid only the values of the gaps corresponding to the speed values of the main vehicular current between $30 \mathrm{~km} / \mathrm{h}$ and $40 \mathrm{~km} / \mathrm{h}$ was adopted.

The values of the acceptance time intervals associated with the following three situations were thus excluded:

- vehicular flow on the flowing main road and characterized by an average speed of less than 30 $\mathrm{km} / \mathrm{h}$. In this case, in fact, the space-time interval between one vehicle and another was often so wide that the test-driver performed the turning or crossing maneuver without selecting any gap between the vehicles of the main traffic flow;

- congested vehicular flow in the main road (average speed well below $30 \mathrm{~km} / \mathrm{h}$ ). This situation generally gave rise to medium / long waiting times by the test-drivers before starting the desired maneuver, with often very short acceptance intervals;

- $\quad$ "fast" traffic flow on the main legs (speed above 40 $\mathrm{km} / \mathrm{h}$ ) with a consequent increase in caution on the part of elderly drivers who were often led to wait a long time for the acceptance interval deemed most appropriate (this gap was overestimated, sometimes assuming unexpectedly high values).

\subsection{Analytic Method}

Following video processing, the collected data were first statistically processed and then analyzed. First, with respect to each of the maneuvers related to each intersection considered, the following data were calculated:

1) the frequencies of the critical gaps;

2) the cumulative frequencies.

In particular, if $n_{i}$ denotes the number of repetitions of the same $\mathrm{i}$-th time interval and $\mathrm{n}$ the total number of measurements performed, the relative frequency of the $\mathrm{i}$-th interval is given by the ratio $n_{i} / n$, while the cumulative frequency $\left(\mathrm{F}_{\mathrm{i}}\right)$ of the $\mathrm{i}$-th measurement itself is given by the following relation:

$$
F_{i}=\sum_{j=1}^{i} f_{j}=\sum_{j=1}^{i} \frac{n_{j}}{n}
$$

The next step was to identify the probability distribution curve that best approximates the cumulative frequency curve, and then plot the curve itself. In the specific case, the use of logistic regression was deemed appropriate, which is a statistical model representing the probability of occurrence of a particular event (such as the acceptance of a time interval) which has the following analytical expression:

$$
\ln \left(\frac{p}{1-p}\right)=a+b \cdot G
$$

Where:

- $\mathrm{p}=$ probability of accepting a time interval of length G;

- $\mathrm{G}=$ acceptance time interval (critical gap) [sec];

- $\quad a, b=$ regression coefficients.

Thus, for each intersection, the probability distribution curves were obtained, evaluating the regression coefficients "a" and "b" for each type of maneuver.

Then, the $50^{\text {th }}$ percentile critical gap was calculated, defined as the time interval accepted by $50 \%$ of the users $\left(\mathrm{G}_{50}\right)$, which was obtained using the previous expression by entering $p=0.50$ and solving for $G$.

\section{Results and Discussion}

A total of 2472 acceptance time intervals (critical gap) were observed and timed, which is distributed as follows:

- $\quad 882$ for right-turn maneuvers;

- 743 for left-turn maneuvers;

- 847 for crossing maneuvers.

Table 2 shows the measured critical gaps divided by the two age groups and distributed for each intersection and for each maneuver.

Critical gaps related to right-turn maneuvers were not measured in intersection $\mathrm{N}^{\circ} 9$ because this maneuver was prohibited. The critical gaps related to left-turn maneuvers were not assessed for intersections $\mathrm{N}^{\circ} 5$ and $\mathrm{N}^{\circ} 8$ (left-turn maneuvers not allowed).

Critical gaps related to crossing maneuvers were not measured for intersections $\mathrm{N}^{\circ} 1, \mathrm{~N}^{\circ} 2, \mathrm{~N}^{\circ} 8$, and $\mathrm{N}^{\circ} 9$ because they are T-type intersections.

Regarding the application of the procedure to determine the $\mathrm{G}_{50}$ values, the research team began with estimating the $\mathrm{G}_{50}$ values divided by the age group for each maneuver and for each of the 9 intersections. Since the analysis of the different values of $50^{\text {th }}$ percentile critical gap $\left(\mathrm{G}_{50}\right)$ for both age groups considered highlighted a high degree of homogeneity in the data with respect to each type of maneuver, it was decided to group all the observed measures for each of the possible maneuvers in the studied intersections, distinguishing them according to the two age groups of the test drivers. The cumulative frequency curves related to all the maneuvers globally associated with the 9 studied intersections were thus plotted, as well as the probability distribution curves obtained by logistic regression (Fig. 3 and Fig. 4). The values of the $50^{\text {th }}$ percentile critical gap $\left(\mathrm{G}_{50}\right)$ resulting from the processing of the experimental data and the regression coefficients related to the corresponding probability distributions are presented in Table 3. 
Table 2. Number of acceptance time intervals selected after investigation

\begin{tabular}{|c|c|c|}
\hline \multirow[b]{2}{*}{ Intersection } & \multicolumn{2}{|c|}{$\begin{array}{l}\text { Measured critical gaps } \\
\text { Right-turn maneuvers }\end{array}$} \\
\hline & Drivers between the ages of 65 and 75 & Drivers over the age of 75 \\
\hline $\mathrm{N}^{\circ} 1$ & 35 & 21 \\
\hline $\mathrm{N}^{\circ} 2$ & 46 & 30 \\
\hline $\mathrm{N}^{\circ} 3$ & 123 & 82 \\
\hline $\mathrm{N}^{\circ} 4$ & 56 & 43 \\
\hline $\mathrm{N}^{\circ} 5$ & 72 & 62 \\
\hline $\mathrm{N}^{\circ} 6$ & 65 & 46 \\
\hline $\mathrm{N}^{\circ} 7$ & 57 & 49 \\
\hline $\mathrm{N}^{\circ} 8$ & 51 & 44 \\
\hline $\mathrm{N}^{\circ} 9$ & 0 & 0 \\
\hline Totals by age group & 505 & 377 \\
\hline \multirow[t]{2}{*}{ Totals by type of maneuver } & \multicolumn{2}{|l|}{882} \\
\hline & \multicolumn{2}{|c|}{$\begin{array}{l}\text { Measured critical gaps } \\
\text { Left-turn maneuvers }\end{array}$} \\
\hline Intersection & Drivers between the ages of 65 and 75 & Drivers over the age of 75 \\
\hline $\mathrm{N}^{\circ} 1$ & 40 & 33 \\
\hline $\mathrm{N}^{\circ} 2$ & 46 & 37 \\
\hline $\mathrm{N}^{\circ} 3$ & 95 & 78 \\
\hline $\mathrm{N}^{\circ} 4$ & 61 & 50 \\
\hline $\mathrm{N}^{\circ} 5$ & 0 & 0 \\
\hline $\mathrm{N}^{\circ} 6$ & 56 & 38 \\
\hline $\mathrm{N}^{\circ} 7$ & 67 & 51 \\
\hline $\mathrm{N}^{\circ} 8$ & 0 & 0 \\
\hline $\mathrm{N}^{\circ} 9$ & 49 & 42 \\
\hline Totals by age group & 414 & 329 \\
\hline \multirow[t]{2}{*}{ Totals by type of maneuver } & \multicolumn{2}{|l|}{743} \\
\hline & \multicolumn{2}{|c|}{$\begin{array}{l}\text { Measured critical gaps } \\
\text { Crossing maneuvers }\end{array}$} \\
\hline Intersection & Drivers between the ages of 65 and 75 & Drivers over the age of 75 \\
\hline $\mathrm{N}^{\circ} 1$ & 0 & 0 \\
\hline $\mathrm{N}^{\circ} 2$ & 0 & 0 \\
\hline $\mathrm{N}^{\circ} 3$ & 119 & 92 \\
\hline $\mathrm{N}^{\circ} 4$ & 150 & 116 \\
\hline $\mathrm{N}^{\circ} 5$ & 81 & 59 \\
\hline $\mathrm{N}^{\circ} 6$ & 57 & 43 \\
\hline $\mathrm{N}^{\circ} 7$ & 72 & 58 \\
\hline $\mathrm{N}^{\circ} 8$ & 0 & 0 \\
\hline $\mathrm{N}^{\circ} 9$ & 0 & 0 \\
\hline Totals by age group & 479 & 368 \\
\hline Totals by type of maneuver & \multicolumn{2}{|l|}{847} \\
\hline Totals & \multicolumn{2}{|l|}{2472} \\
\hline
\end{tabular}


a)

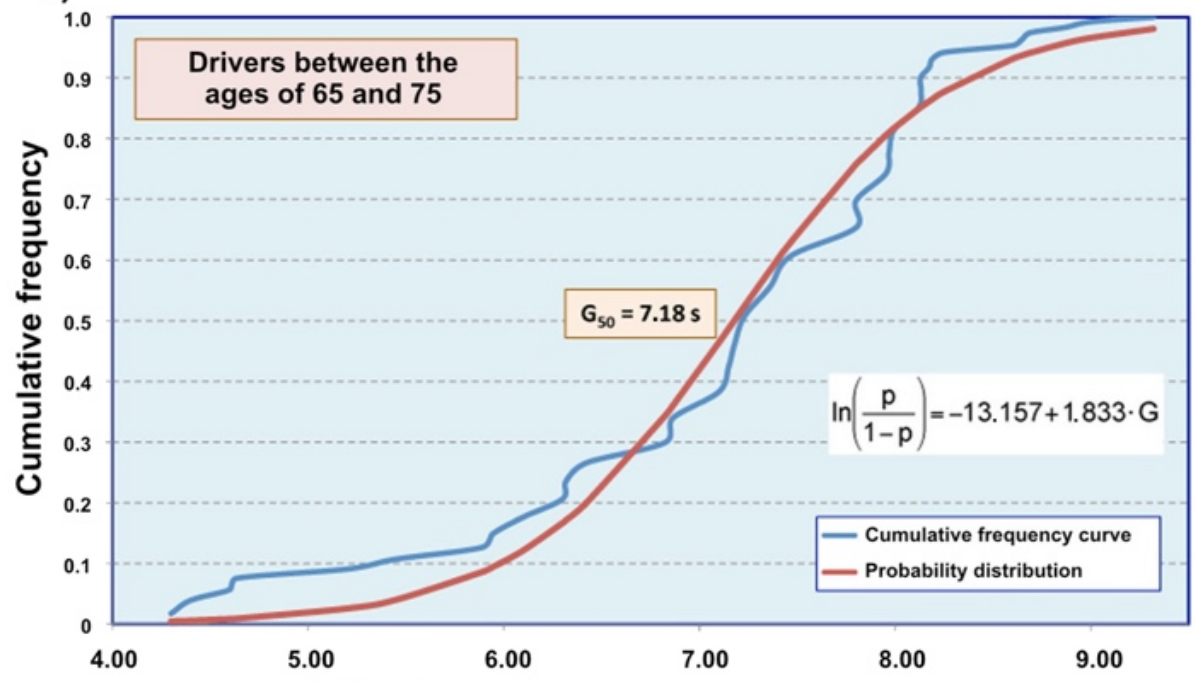

b)

Critical gap (s) - Right-turn maneuvers

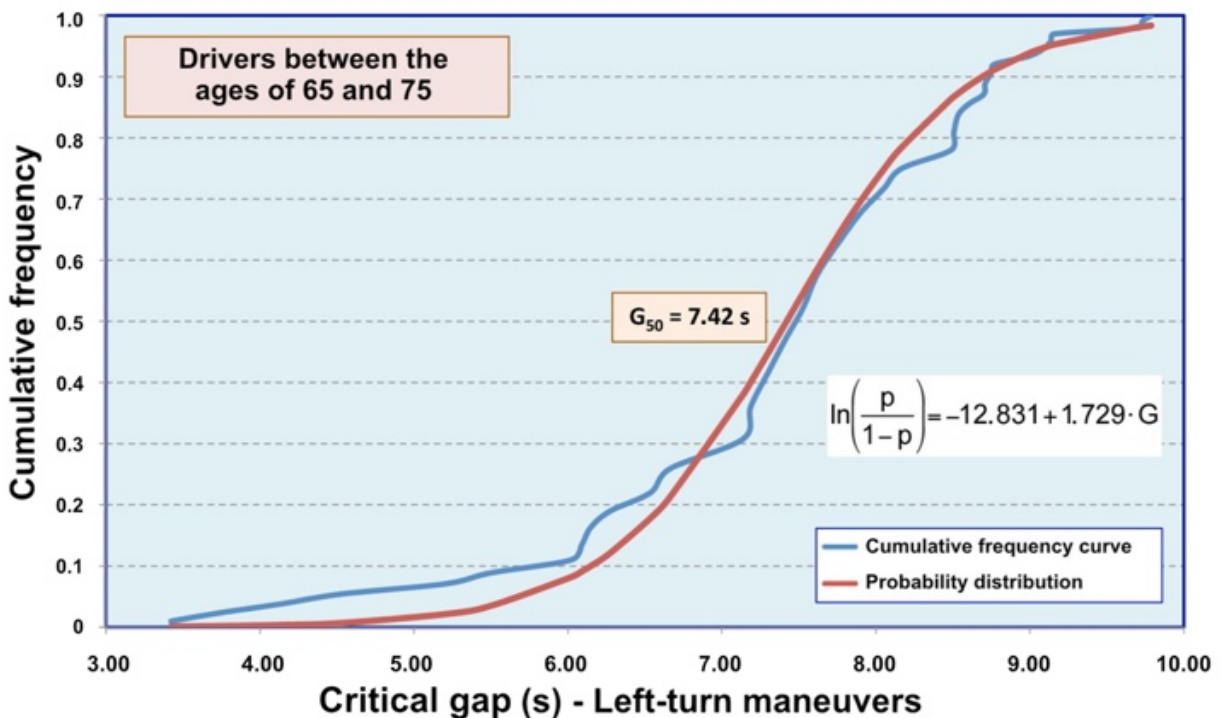

c)

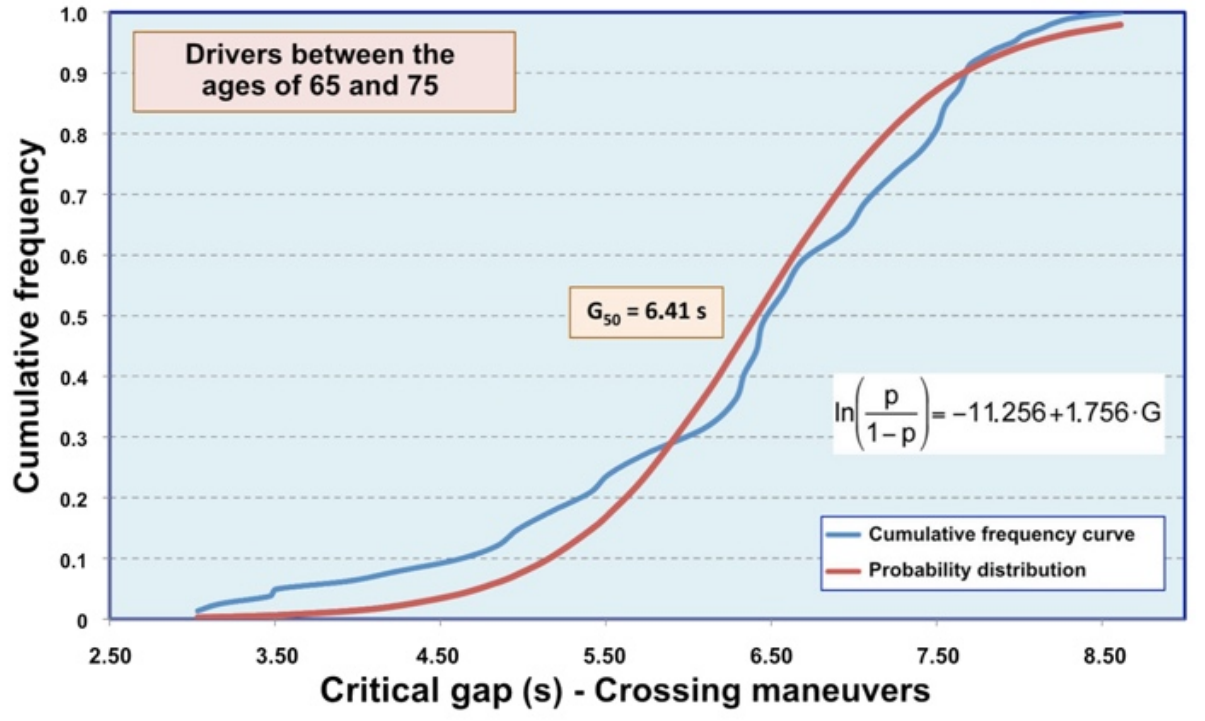

Figure 3. Statistical analysis of the critical gaps measured during the experimental investigation (drivers between the ages of 65 and 75 ) 
d)
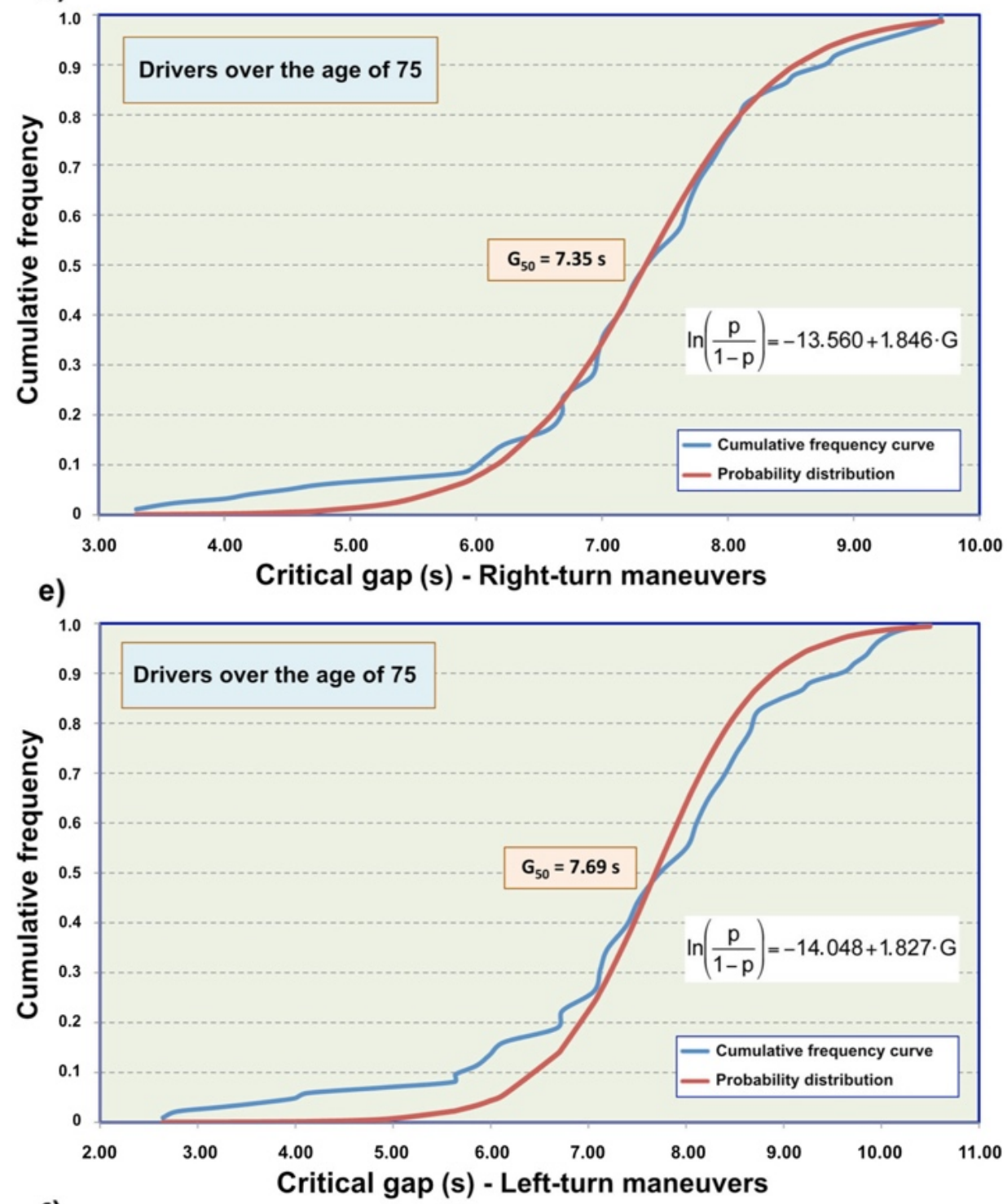

f)

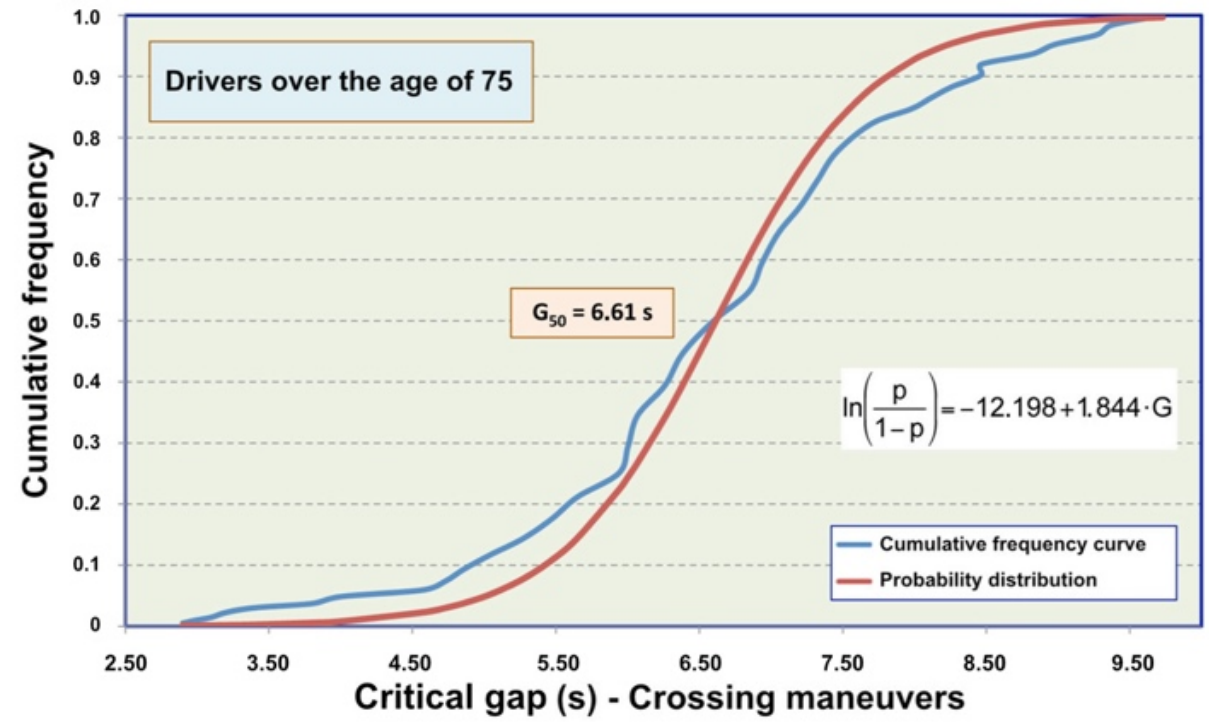

Figure 4. Statistical analysis of the critical gaps measured during the experimental investigation (drivers over the age of 75) 
Table 3. $\mathrm{G}_{50}$ values and regression coefficients related to the probability distributions

\begin{tabular}{|c|c|c|c|c|c|}
\hline & Driver & tween the ages of 65 and 7 & & Drivers over the age of 75 & \\
\hline Maneuver & $\mathrm{G}_{50}(\mathrm{~s})$ & Regression coefficients & $\mathrm{G}_{50}(\mathrm{~s})$ & Regression coefficients & $\mathrm{G}_{50}(\mathrm{~s})$ (Average values) \\
\hline \multirow{2}{*}{ Right-turn } & \multirow{2}{*}{7.18} & $a=-13.157$ & \multirow{2}{*}{7.35} & $a=-13.560$ & \multirow{2}{*}{7.25} \\
\hline & & $\mathrm{b}=1.833$ & & $\mathrm{~b}=1.846$ & \\
\hline \multirow{2}{*}{ Left-turn } & \multirow{2}{*}{7.42} & $\mathrm{a}=-12.831$ & \multirow{2}{*}{7.69} & $\mathrm{a}=-14.048$ & \multirow{2}{*}{7.55} \\
\hline & & $\mathrm{b}=1.729$ & & $\mathrm{~b}=1.827$ & \\
\hline \multirow{2}{*}{ Crossing } & \multirow{2}{*}{6.41} & $a=-11.256$ & \multirow{2}{*}{6.61} & $a=-12.198$ & \multirow{2}{*}{6.5} \\
\hline & & $b=1.756$ & & $\mathrm{~b}=1.844$ & \\
\hline
\end{tabular}

The data presented in Table 3 show that the acceptance intervals of drivers over 75 years old are always larger, on average by about 0.2 seconds, than those of users up to 75 years old. As expected, the largest difference ( 0.27 seconds) is found for the left-turn maneuver, the one that most stresses the psycho-physical performance of the drivers.

It is interesting to note that for all older drivers included in the experimental study, both turning maneuvers (left and right) require a fairly similar level of difficulty. This is evidenced by similar values of $\mathrm{G}_{50}$ in the case of right-turn maneuvers (the average value of $\mathrm{G}_{50}$, calculated as the average of the two values of $\mathrm{G}_{50}$ with respect to the two age groups, is equal to 7.25 seconds) and for left-turn maneuvers (average value of $\mathrm{G}_{50}$ equal to about 7.55 seconds). For the crossing maneuver, on the other hand, the average value of $\mathrm{G}_{50}$ is about 6.5 seconds, which is about 1 second lower than the values of $G_{50}$ for the other two maneuvers.

These results can be compared with the main international references. Table 4 shows the critical gap values $\left(\mathrm{G}_{50}\right)$ proposed by Green Book (2018) and by HCM (2016) $[40,42]$, which are currently the authoritative technical references for the verification of sight distances at intersections and, in general, for the design of the elements that characterize road networks worldwide. It can be noted that the average value of the critical gap related to older drivers performing the crossing maneuver (equal to approximately 6.5 seconds) is identical to the value proposed by Green Book [40], while it exceeds the value proposed by HCM [42] by 0.3 seconds. Similarly, the average value of the critical gap obtained with our study in the case of older drivers performing the left-turn maneuver (equal to $7.55 \mathrm{~s}$ ) is exactly the same as that of Green Book [40], while it exceeds the value suggested by the HCM [42] by 0.4 seconds.

Table 4. Critical gap values proposed by Green Book (2018) and by HCM (2016)

\begin{tabular}{cccc}
\hline & \multicolumn{3}{c}{ Critical gap $\left(\mathrm{G}_{50}\right)$} \\
\cline { 2 - 4 } & Right-turn & Left-turn & Crossing \\
\hline HCM (2016) & $6.2 \mathrm{~s}$ & $7.1 \mathrm{~s}$ & $6.5 \mathrm{~s}$ \\
\hline Green Book (2018) & $6.5 \mathrm{~s}$ & $7.5 \mathrm{~s}$ & $6.5 \mathrm{~s}$ \\
\hline
\end{tabular}

Thus, with respect to crossing and left-turn maneuvers, the sight distance checks proposed by the Green Book [40] are also compatible with the expectations of older drivers. This leads the authors of this study to propose the use of the Green Book [40] methodology for intersection sight distance checks in the case of left-turn and crossing maneuvers. In fact, this methodology seems to be sufficient, without the need for modification, to ensure the execution of the above maneuvers with the same level of safety for all categories of users (including the elderly).

On the other hand, the HCM 2016 [42] provides slightly lower $\mathrm{G}_{50}$ values for intersection and left-turn maneuvers than the Green Book [40]. So, this does not seem to fully meet the safety requirements that should be ensured for users over 65 years of age.

For the right-turn maneuver, other considerations must be made. The experimentally determined value of the distance (average $\mathrm{G}_{50}$ equal to 7.25 seconds) is about 0.7 seconds higher than that of the Green Book [40] and even about 1 second higher than the corresponding value given by the HCM [42].

Therefore, the obstacle-free area to the left of elderly drivers waiting with their vehicles to cross the stop line to turn right must be significantly larger than that which can be calculated by both the Green Book and the HCM [40, 42]. In the case of elderly road users, the main international references for intersection distance sight checks do not appear to provide an adequate level of safety for elderly people making a right-turn maneuver.

If the safety needs of users over 65 years of age are to be taken into account, the visibility criteria based on the critical gap should be revised and modified to increase the value of the critical gap to be used for visibility checks in the case of right-turns at intersections with 3 or 4 legs, where the minor legs are stop-controlled.

The results of this study can also be discussed in the light of the current Italian legislation on the design of intersections [53]. The Italian legislation in question proposes a different criterion from the one used in the Green Book and the HCM [40, 42]. According to M.D. 19/04/2006 (sect. 4.6) [53], visibility in intersections regulated by the stop sign is guaranteed on the secondary legs if the areas delimited by the sight triangles are free of obstacles. The sight triangles must be established under the hypothesis that the driver of the vehicle on the minor road, 
located at a distance of 3 meters from the stop line, can see the vehicles on the major road, for a distance of length ISD (Intersection Sight Distance), which can be evaluated with the following expression (in meters):

$$
\mathrm{ISD}=0.278 \cdot \mathrm{S} \cdot \mathrm{t}
$$

Where:

- $\quad \mathrm{S}=$ characteristic speed of major $\operatorname{road}(\mathrm{km} / \mathrm{h})$, equal to the design speed determined by the speed diagrams or, in the presence of speed limits, the value prescribed by the signs;

- $\quad \mathrm{t}=$ maneuver time $(\mathrm{s}) ; \mathrm{t}=$ maneuver time $(\mathrm{s}) ;$ it is set equal to 6 seconds (sum of the perception and reaction time and the time needed to clear the intersection). This value must be increased by one second for each percentage point of longitudinal gradient of the minor road above $2 \%$.

The Italian legislation [53] for the calculation of sight triangles does not distinguish in any way the type of maneuver to be performed and therefore the ISD distance calculated with the previous expression must be used to verify the visibility conditions associated with the execution of all the typical maneuvers of the intersection areas (crossing, right-turn and left-turn).

Table 5 shows the values of ISD calculated with the criterion provided by the Italian legislation [53] and with the critical gap-based method, assuming the average values of $\mathrm{G}_{50}$ for each of the three maneuvers obtained as a result of the experimental study. The table also shows the increases $\left(\Delta_{\mathrm{ISD}}\right.$, expressed as a percentage) are attributed to the sight distances according to Italian legislation, due to the visibility needs of elderly users, taken into account by applying the acceptance gap criterion with the values of $\mathrm{G}_{50}$ obtained in the present study.

Table 5 shows that it is necessary to increase the ISD values proposed by the Italian standards by the following percentages to meet the safety requirements for users over 65 years of age:

- $\quad 20-22 \%$ for the right-turn maneuver;

- $\quad 25-27 \%$ for the left-turn maneuver;

- $\quad 8-10 \%$ for the crossing maneuver.

Table 5. ISD values calculated with the Italian legislation and with the critical gap method

\begin{tabular}{|c|c|c|c|c|c|c|c|}
\hline \multirow{3}{*}{ Speed $(\mathbf{k m} / \mathbf{h})$} & \multirow{3}{*}{$\begin{array}{c}\text { All maneuvers } \\
\text { M.D. 19/04/2006 } \\
\text { ISD (m) }\end{array}$} & \multicolumn{2}{|c|}{ Right-turn } & \multicolumn{2}{|c|}{ Left-turn } & \multicolumn{2}{|c|}{ Crossing } \\
\hline & & \multicolumn{2}{|c|}{$\mathrm{G}_{50}=7.25 \mathrm{sec}$} & \multicolumn{2}{|c|}{$\mathrm{G}_{50}=7.55 \mathrm{sec}$} & \multicolumn{2}{|c|}{$\mathrm{G}_{50}=6.5 \mathrm{sec}$} \\
\hline & & ISD (m) & $\Delta_{\text {ISD }}(\%)$ & ISD (m) & $\Delta_{\text {ISD }}(\%)$ & ISD (m) & $\Delta_{\text {ISD }}(\%)$ \\
\hline 20 & 33 & 40 & 22.1 & 42 & 27.1 & 36 & 9.4 \\
\hline 30 & 50 & 60 & 20.8 & 63 & 25.8 & 54 & 8.3 \\
\hline 40 & 67 & 81 & 20.2 & 84 & 25.2 & 72 & 7.8 \\
\hline 50 & 83 & 101 & 21.3 & 105 & 26.3 & 90 & 8.8 \\
\hline 60 & 100 & 121 & 20.8 & 126 & 25.8 & 108 & 8.3 \\
\hline 70 & 117 & 141 & 20.5 & 147 & 25.5 & 126 & 8.0 \\
\hline 80 & 133 & 161 & 21.1 & 168 & 26.1 & 144 & 8.6 \\
\hline 90 & 150 & 181 & 20.8 & 189 & 25.8 & 163 & 8.3 \\
\hline 100 & 167 & 201 & 20.6 & 210 & 25.6 & 181 & 8.1 \\
\hline
\end{tabular}


It is clear that Italian legislation [53] is totally inadequate to take into account the needs of elderly road users, particularly with regard to the safe execution of left and right-turn maneuvers.

The fact that sight distances need to be increased by more than $20 \%$ to optimize safety when turning right, and by more than $25 \%$ for left-turn maneuvers, leads the authors of this study to hope above all that:

1) in a future revision of Italian legislation on the design of road intersections, visibility criteria will be adopted, and differentiated according to the type of maneuver and the acceptance gap, and thus more closely related to the real psycho-physical characteristics of users approaching from the minor legs,

2) the above visibility criteria are based on $\mathrm{G}_{50}$ values, suitable to take into account the expectations of elderly drivers.

\section{Conclusions}

In this study, the authors investigated in detail a particular aspect of road safety related to the behavioral performance of elderly drivers in the execution of the three possible maneuvers (right-turn, left-turn, crossing) at stop-controlled intersections. The experimental study aimed at estimating the acceptance intervals at stop-controlled intersections by a sample of test drivers divided into two age groups. The need arose to diversify the parameters used to test sight distances in relation to the possible maneuvers that can be performed. This is in line with the main international regulations.

The experimentally determined values of the critical gap for the left-turn and crossing maneuvers, which represent the main result of this study, were found to be compatible with the values found in the main reference manuals for road design (HCM 2016 and the Green Book 2018 [40, 42]). In particular, the values of the $50^{\text {th }}$ percentile critical gap proved to be perfectly aligned with those reported in the Green Book [40].

The value of the critical $50^{\text {th }}$ percentile gap $\left(\mathrm{G}_{50}\right)$ associated with the right-turn maneuver obtained from the experimental investigation was similar to that associated with the left-turn maneuver and therefore, it was significantly higher than the value used in the technical manuals. This is obviously an indication of a very similar level of difficulty of the older drivers in performing both turning maneuvers at stop-controlled intersections.

With regard to Italian legislation, the results of this study have highlighted the need to take into account the various operational difficulties associated with the possible maneuvers at the intersections. In fact, the theoretical approach of the Italian regulations, based on a criterion that does not differentiate the way in which the three maneuvers are carried out, is completely disconnected from the actual way in which users (including the elderly) operate. This would obviously lead to a complete revision of the criteria for checking sight distances at stop-controlled intersections.

It is therefore desirable, in the context of the indispensable revision of technical standards in the road design sector, to pay particular attention to those design parameters that are directly and indirectly related to variables conditioned by human behavior. From this point of view, it is impossible to ignore the needs of a user group such as the elderly, who, as we know, are increasingly present both in Italy and in the rest of Europe and the world.

\section{REFERENCES}

[1] Vespa J., Armstrong D. M., Medina L., "Demographic Turning Points for the United States: Population Projections for 2020 to 2060," Washington, DC: US Department of Commerce, Economics and Statistics Administration, US Census Bureau, 2018.

https://www.census.gov/content/dam/Census/library/public ations/2020/demo/p25-1144.pdf

[2] National Highway Traffic Safety Administration. "Older Population: 2018 Data," Traffic Safety Facts. Report No. DOT HS 812 928. National Highway Traffic Safety Administration, National Center for Statistics and Analysis, 2020. https://crashstats.nhtsa.dot.gov/Api/Public/ViewPubli - cation $/ 812928$

[3] European Statistical Institute - Eurostat. https://ec.europa.eu/eurostat (accessed Jan., 2021).

[4] Pomidor A., "Clinician's Guide to Assessing and Counseling Older Drivers," Washington, DC: National Highway Traffic Safety Administration, 2019. http://safemobilityfl.co $\mathrm{m} / \mathrm{pdfs} /$ CliniciansGuide/CliniciansGuideOlderDriversComp lete4thEdition.pdf

[5] European Commission - An official website of the European Union. Online available from https://ec.europa.eu/info/inde X_en (accessed Jan., 2021).

[6] Distefano N., Pulvirenti G., Leonardi S., "Neighbourhood walkability: Elderly's priorities," Research in Transportation Business and Management, 100547, 2020. DOI: 10.1016/j.rtbm.2020.100547

[7] Leonardi S., Distefano N., Pulvirenti G., "Identification of road safety measures for elderly pedestrians based on k-means clustering and hierarchical cluster analysis," Archives of Transport, 56(4), 107-118, 2020. DOI: 10.5604/01.3001.0014.5630

[8] Pulvirenti G., Distefano N., Leonardi S., "Elderly Perception of Critical Issues of Pedestrian Paths," Civil engineering and Architecture, 8 (1), 26-37, 2020. DOI: 10.13189/cea.2020.080104

[9] Classen S., "Special issue on older driver safety and community mobility," Am. J. Occupat. Ther. 64, 211-214, 2010. DOI: 10.5014 /ajot.64.2.211 
[10] Karthaus M., Falkenstein M., "Functional changes and driving performance in older drivers: assessment and interventions," Geriatrics 1 (12), 2016. DOI: $10.3390 /$ geriatrics 1020012

[11] Samuel S., Yamani Y., Fisher D. L., "Large reductions are possible in older driver crashes at intersections," Clin. Exper. Optometry 99, 419-424, 2016. DOI: 10.1111 /cxo.12 443

[12] Benekohal R., Resende P., Shim E., Michaels R., Weeks B., "Highway operations problems of elderly drivers in Illinois," Report No. FHWA-IL-023. Federal Highway Administration, US Department of Transportation, Springfield, USA, 1992.

[13] Owsley C., Sekuler R., Siemensen D., "Contrast sensitivity throughout adulthood," Vision Research, 23(7), 689-699, 1983. DOI: 10.1016/0042-6989(83)90210-9

[14] Shinar D., Scheiber F., "Visual requirements for safety and mobility of older drivers," Human Factors, 33(5), 507-519, 1991. DOI: $10.1177 / 001872089103300503$

[15] Stelmach G., Goggin N., Garcia-Colera A., "Movement specification time with age," Experimental Aging Research, 13, 39-46, 1987. DOI: 10.1080/03610738708259298

[16] Stelmach G., Nahom A., "Cognitive-motor abilities of the elderly driver," Human Factors, 34(1), 53-65, 1992. DOI: 10.1177/001872089203400107

[17] Kausler D., "Experimental psychology, cognition, and human aging," 2nd ed. New York, USA: Springer-Verlag, 1991.

[18] Morris R., Craik F., Gick M., "Age differences in working memory tasks: the role of secondary memory and the central executive system," Quarterly Journal of Experimental Psychology: Human Experimental Psychology, 42(1-A), 67-86, 1990. DOI: 10.1080/14640749008401208

[19] Stamatiadis N., Taylor W., McKelvey F., "Elderly drivers and intersection accidents.," Transportation Quarterly, 45(3), 559-571, 1991. https://hdl.handle.net/2027/uc1.c104 686033 ? urlappend $=\% 3$ Bseq $=385$

[20] Brébion G., Smith M., Ehrlich M., "Working memory and aging: deficit or strategy differences," Aging, Neuropsychology and Cognition, 4(1), 58-73, 1997. DOI: $10.1080 / 13825589708256636$

[21] Madden D., Connelly L., Pearce Y., "Aging and focussed attention," Psychology and Aging, 9(4), 528-538, 1994. https://www.monash.edu/_data/assets/pdf_file/0007/21688 0/muarc157.pdf

[22] McGwin G. Jr., Chapman V., Owsley C., "Visual risk factors for driving difficulty among older drivers," Accid. Anal. Prevent. 32, 735-744, 2000. DOI: 10.1016/S0001-4575(99) 00123-2

[23] Langford J., Koppel S., "Epidemiology of older driver crashes - Identifying older driver risk factors and exposure patterns," Transport. Res. Part F 9, 309-321, 2006. DOI: 10.1016/j.trf.2006.03.005

[24] Bédard M., Guyatt G. H., Stones M., Hirdes J. P., "The independent contribution of driver, crash, and vehicle characteristics to driver fatalities," Accid. Anal. Prevent. 34, 717-727, 2002. DOI: 10.1016/S0001-4575(01)00072-0
[25] Savolainen P. T., Kawa J. M., Gates T. J., "Examining Statewide Public Perceptions of Roundabouts Through a Web-Based Survey," Transportation Research Record: Journal of the Transportation Research Board, 2312, 25-33, 2012. DOI: $10.3141 / 2312-03$

[26] Leonardi S., Distefano N., Pulvirenti G., "Italians' public opinion on road roundabouts: A web-based survey," AIIT 2nd International Congress on Transport Infrastructure and Systems in a changing world (TIS ROMA 2019), 23rd-24th September 2019, Rome, Italy. Transportation Research Procedia 45:293-300. DOI: 10.1016/j.trpro.2020.03.019

[27] Insurance Institute for Highway Safety, Arlington, VA. Online available from http://www.iihs.org/iihs/sr/statusrepo rt/article/42/3/1 (accessed Jan., 2021).

[28] Staplin L., Lococo K., Byington S., Harkey D., "Highway design handbook for older drivers and pedestrians," Report No. FHWA-RD-01-103. Federal Highway Administration, US Department of Transportation, Washington DC, USA, 2001. https://www.fhwa.dot.gov/publications/research/ safety/humanfac/01103/

[29] Cox A. E., Cicchino J. B., "Continued trends in older driver crash involve rates in the United States: Data through 2017-2018," Journal of Safety Research, 77(1), 288-295, 2021. DOI: 10.1016/j.jsr.2021.03.013

[30] Villalba J., Kirk A., Stamatiadis N., "Effects of age and cohort on older drivers," Proceedings of the 2001 ATT Conference and Exhibition, Vol. 1, pp. 113-118, Barcelona, Spain, October 1-3, 2001. DOI: 10.4271/2001-01-3349

[31] Mayhew D., Simpson H., Ferguson S., "Collisions involving senior drivers: high risk conditions and locations," Traffic Injury Prevention, 7(2), 117-124, 2006. DOI: $10.1080 / 15389580600636724$

[32] Haule H., Sando T., Kitali A., Angel M., Ozguven E., "Influence of intersection characteristics on elderly crash involvement," Proceedings Transportation Research Board 97th Annual Meeting, Washington, D.C., 2018.

[33] Park S. J., Subramaniyam M., Kim S. E., Hong S., Lee J. H., Jo C. M., "Older driver's physiological response under risky driving conditions - overtaking, unprotected left turn," Proceedings of the AHFE 2016 International Conference on Digital Human Modeling and Simulation, Vol. 481, ed V. Duffy (Cham: Springer International Publishing), 107-114, 2017. DOI: $10.1007 / 978-3-319-41627-4 \_11$

[34] Bao S., Boyle L. N., "Age-related differences in visual scanning at median-divided highway intersections in rural areas," Accid. Anal. Prevent. 41, 146-152, 2009. DOI: 10.1016/j.aap.2008.10.007

[35] Retting R. A., Weinstein H. B., Solomon M. G., "Analysis of motor-vehicle crashes at stop signs in four US cities," J. Saf. Res. 34, 485-489, 2003. DOI: 10.1016/j.jsr.2003.05.001

[36] Laberge J. C., Creaser J. I., Rakauskas M. E., Ward N. J., "Design of an intersection decision support (IDS) interface to reduce crashes at rural stop-controlled intersections," Transp. Res. Part C: Emerg. Technol. 14, 39-56, 2006. DOI: 10.1016/j.trc.2006.03.001

[37] Chovan J. D., Tijerian L., Everson J. H., Pierowicz J. A., Hendricks D. L., "Examination of intersection left turn across path crashes and IVHS countermeasures," DOT HS 
808 154. National Highway Traffic Safety Administration, 1994.

[38] Spek A. C. E., Wieringa P. A., Janssen W. H., "Intersection approach speed and accident probability," Transp. Res. Part F: Traffic Psychol. Behav. 9, 155-171, 2006. DOI: 10.1016/j.trf.2005.10.001

[39] Alexander J., Barham P., Black I., "Factors influencing the probability of an incident at a junction: results from an interactive driving simulator," Accid. Anal. Prev. 34, 779-792, 2002. DOI: 10.1016/S0001-4575(01)00078-1

[40] American Association of State Highway and Transportation Officials (AASHTO), "A Policy on Geometric Design of Highways and Streets," Washington, DC, 7th Edition, 2018.

[41] Harwood D., Mason J., Brydia R., "Sight distance for stop-controlled intersections based on gap acceptance," Transp. Res. Rec. 1701, 32-41, 2000. DOI: 10.3141/1701-05

[42] Highway Capacity Manual, "A Guide for Multimodal Mobility Analysis," Sixth Edition. Washington, D.C. Transportation Research Board, 2016.

[43] Yan X., Radwan E., Guo D., "Effects of major-road vehicle speed and driver age and gender on left-turn gap acceptance," Accid. Anal. Prev. 39 (4), 843-852, 2007. DOI: 10.1016/j.aap.2006.12.006

[44] Bottom C. G., Ashworth R., "Factors affecting the variability of driver gap-acceptance behavior," Ergonomics, 21(9), 721-734, 1978.

[45] Nabaee S., Moore D., Hurwitz D., "Revisiting driver behavior at unsignalized intersections: Time of day implications for two-way left turn lanes (TWLTL)," Conference: Driving Assessment Conference. Lake Tahoe, California, 2011. DOI: 10.17077/drivingassessment.1430

[46] Pollatschek M. A., Polus A., Livneh M., "A decision model for gap acceptance and capacity at intersections," Transportation Research Part B: Methodological, 36(7), 649-663, 2002. DOI: 10.1016/S0191-2615(01)00024-8

[47] Mahmassani H., Sheffi Y., "Using gap sequences to estimate gap acceptance functions," Transportation Research Part B: Methodological, 15(3), 143-148, 1981. DOI: 10.1016/0191-2615(81)90001-1

[48] Tupper S. M., Knodler M. A. Jr., Hurwitz D. S., "Connecting gap acceptance behavior with crash experience," 3rd International Conference on Road Safety and Simulation. Purdue University. Transportation Research Board, 2011. http://onlinepubs.trb.org/onlinepub s/conferences/2011/RSS/1/Tupper,S.pdf

[49] Beanland V., Lenné M. G., Candappa N., Corben B., "Gap acceptance at stop-controlled T-intersections in a simulated rural environment," Transp. Res. Part F Traffic Psychol. Behav. 20, 80-89, 2013. DOI: 10.1016/j.trf.2013.05.006

[50] Cicchino J. B., McCartt A. T., "Critical older driver errors in a national sample of serious U.S. Crashes," Accid. Anal. Prev. 80, 211-219, 2015. DOI: 10.1016/j.aap.2015.04.015

[51] Mitsopoulos-Rubens E., Triggs T. J., Regan M., "Comparing the gap acceptance and turn time patterns of novice with experienced drivers for turns across traffic," 5th International Driving Symposium on Human Factors in Driver Assessment, Training and Vehicle Design. Big Sky MT, United States. pp. 228-235, 2009. https://ir.uiowa.edu/cgi/viewcontent.cgi? article=1326\&co ntext $=$ drivingassessment

[52] Lyles R. W., Staplin L., "Age differences in motion perception and specific traffic maneuver problems," Transp. Res. Rec. 1325, 23-33, 1991. http://onlinepubs.trb.org/ Onlinepubs/trr/1991/1325/1325-004.pdf

[53] Italian Ministry of Infrastructure and Transport. "Ministerial Decree No 19/04/2006 - Norme funzionali e geometriche per la costruzione delle intersezioni stradali (translation: Functional and geometric rules for the construction of road intersections)," GU n. 170, 24/07/2006. https://www.mit.g ov.it/mit/mop_all.php?p_id=13799

[54] Italian Ministry of Infrastructure and Transport. Italian Road Code. "Legislative Decree n. 285 of 30 April 1992 and subsequent modifications - Codice della strada (translation: Italian Road Code)," GU n. 114, 18/05/1992. https://www.gazzettaufficiale.it/dettaglio/codici/strada/1_0 $-1$ 